\title{
Fricke, Carola (2020): European Dimension of Metropolitan Policies. Policy Learning and Reframing of Metropolitan Regions.
}

\author{
Peter Schmitt
}

Received: 27 November 2020 - Accepted: 13 January 2021 - Published online: 17 February 2021

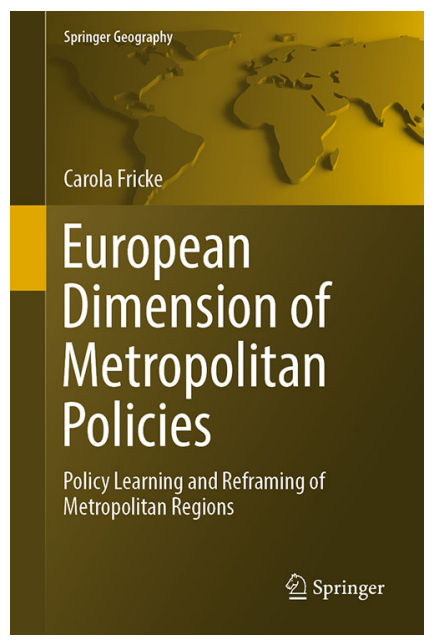

Thinking of metropolitan regions in a relational perspective, one key characteristic is their embeddedness in multi-scalar flows of policy ideas, concepts and other normative articulations, which may stabilise them as political actors and offer them agency to develop transnational linkages (McCann/ Ward 2011; Jonas/Moisio 2018). Within the EU, metropolitan policies are mobilised by a rather large array of different types of (political) actors, and the policies bounce back and forth among them. In doing so, they eventually mutate and are re-packaged in order to feed into different territorial and institutional contexts (Zimmermann 2020). However,

Dr. Peter Schmitt, Department of Human Geography, Stockholm University, 10691 Stockholm, Sweden peter.schmitt@humangeo.su.se

(c) (1) (2) ( 2021 Schmitt; licensee oekom verlag. This Open Access article is published under the Creative Commons Attribution-ShareAlike 4.0 International Licence. capturing the various policy forms that are mobilised, interpreting their underlying rationalities and analysing what they eventually imply in terms of "Europeanisation" is far from trivial, due to "the fragmented character of metropolitan policies as a multifaceted policy field in Europe" (p. 7). Carola Fricke uncovers these and other complexities in her comprehensive and detailed $\mathrm{PhD}$ study, which the present book is based upon.

Her research can be understood as a wide-ranging tracing of the Europeanisation of metropolitan policies, which is understood as a circular process. To this end, she analyses the multi-scalar polity in which metropolitan regions are embedded. The study includes an in-depth analysis of the European dimension of metropolitan policies in two case-study regions, Lyon and Stuttgart, a related investigation of national policy frames and developments in France and Germany, and finally, a study of metropolitan policies that originate from the multifaceted institutional landscape within the European Union. She thus provides profound and evidence-informed answers to the following main research questions: "i) How do metropolitan policies change? ii) How does the Europeanisation of metropolitan policies take place? iii) How do processes of policy learning and reframing contribute to the change of metropolitan policies?" (p. 6).

Drawing upon interpretative policy analysis, Carola Fricke investigates the contextual embeddedness of metropolitan policies and multi-level comparisons. This means that instead of using a traditional comparative research design based on methodological territorialism, she sheds light on the interrelations within the European multi-level polity. As she puts it, this polity "cannot be compared as a neatly layered cake [...] it resembles a spaghetti bowl of networks or at least a marble cake with patches of different 
dough" (p. 341). As the above research questions indicate, she is specifically interested in exploring path dependencies and critical junctures. In doing so, she focuses specifically on incidents and changing conditions that have shaped the European dimension of metropolitan policies in the past 25 years or so. To that end, she draws upon almost 40 semistructured expert interviews and extensive analysis of policy documents.

Furthermore, the comparative methodological framework is informed by a fairly comprehensive and interdisciplinary synopsis of the prevailing academic work, which comprises debates around metropolitan regions, metropolitan policies, multi-level governance and Europeanisation, as well as accounts of policy transfer and learning and the application of strategies, concepts and metaphors. She also develops a strong argument for why she uses 'frame analysis' instead of other potential analytical frameworks for studying and comparing policy learning in regard to her 'cases'. Overall, one feels that the author struggles slightly with the many complementary and partly overlapping perspectives and semantics that are provided in the literature. This may sound like a subtle criticism, but it also reveals that Carola Fricke strives for accuracy and completeness in her work.

In three chapters she presents the empirical findings of her multi-scalar analysis. It becomes clear that the two case regions, Lyon and Stuttgart, can be seen as exceptional forerunners in engaging with the European dimension of metropolitan regions. Carola Fricke also reveals a number of interesting commonalities between the two, such as their institutional arrangements, their engagement in European networks, and the role of dedicated personalities in key positions. More differences can be distilled from the analysis of the European dimension of French and German metropolitan policies. She discloses how and why the underlying rationalities regarding the role and function of metropolitan regions in national politics originally differed in the two countries, but also shows that the political responses in France and Germany have converged in the past twenty years or so. The analysis of the 'EU-scale' reveals that although metropolitan regions do not represent an explicit policy frame of the EU due to their lack of formal competencies, metropolitan policies have been implicitly addressed by using a wide array of different channels and formats. Examples of these channels and formats are policy documents, funding programmes and lobbying, which have been promoted by different EU institutions (e.g. the European Commission, European Committee of the Regions, European Economic and Social Committee) and transnational networks or other initiatives (such as METREX, the Network of European Metropolitan Regions and Areas) since roughly the mid-1990s. Similar to the analysis of the re- gional and national scale, Carola Fricke exposes how different rationales that underpin normative policy positions have gradually changed, how different funding schemes and instruments have opened up new avenues for addressing metropolitan issues, and how policy learning has been triggered by policy-induced research such as that provided by the ESPON programme (the European Territorial Observation Network).

What is specifically intriguing from my perspective is her analysis of the different prevailing understandings of 'the metropolitan', how these ontologies came into being and, finally, how they were re-framed by various powerful actors, coalitions and sponsors. One example of this is that she reveals fruitful insights into how metropolitan regions are conceptualised and constructed, e.g. by drawing upon problem-oriented definitions, by referring to internal functional interdependencies, by using metaphors such as 'motors of economic development', and, finally, by suggesting their integration into related concepts, such as urban-rural partnerships. Similarly, another key merit of her study is that she exposes how policy learning across different scales and contexts takes place. To that end, she manages to elegantly link together the existing "dualism between broader processes of the policy diffusion of metropolitan concepts and their context-specific translations and reinterpretations" (p. 333).

Overall, Carola Fricke has presented a comprehensive and extremely detailed analysis of the role of metropolitan regions in a European perspective. The book is wellwritten and structured and provides a number of invaluable insights into the complex role of metropolitan regions, here understood as European political actors which have developed agency in various contexts and on different scales in recent years. However, despite the effort to achieve comprehensiveness and the methodological limitations that are inherent within the interpretative tradition of policy analysis, the reader sometimes may wish to learn more about the underlying power games and conflicts, the reasons for coalition building, and other mechanisms that are usually at play in the world of politics and strategic spatial planning. The author herself is aware of these limitations, since each decision on the research design excludes other interesting paths. As such, the book can be considered as an extensive synthesis of the issues addressed, underpinned by various theoretical perspectives stemming from different academic communities or disciplines (such as political sciences, planning studies and human geography) and well-informed by the empirical research undertaken by the author. The book does not necessarily embark on new theoretical or methodological paths but apparently that was not the intention. Instead Carola Fricke's work should be understood as an important cornerstone in the field of European metropolitan 
studies, since it offers a conceptually rich and empirically well-informed account of where we are (or how far we have come) regarding the European dimension of metropolitan policies in the year 2020 .

\section{Complete bibliographic information of the reviewed work:}

Fricke, Carola (2020): European Dimension of Metropolitan Policies. Policy Learning and Reframing of Metropolitan Regions. Cham: Springer. 348 pages, 14 tables, 16 figures

\section{References}

Jonas, A.E.G.; Moisio, S. (2018): City regionalism as geopolitical processes: A new framework for analysis. In: Progress in Human Geography 42, 3, 350-370. https://doi.org/10.1177/0309132516679897

McCann, E.; Ward, K. (eds.) (2011): Mobile Urbanism: Cities and Policymaking in the Global Age. Minneapolis. Zimmermann, K. (2020): From Here to There: Mapping the Metropolitan Politics of Policy Mobilities. In: Zimmermann, K.; Galland, D.; Harrison, J. (eds.): Metropolitan Regions, Planning and Governance. Cham, 97-115. https://doi.org/10.1007/978-3-030-25632-6_6 